\title{
Research on Photography Teaching Based on the Digital Age
}

\author{
Yingchun An
}

Hohhot Minzu College, Hohhot, Inner Mongolia, 010051, China

\author{
Keywords: Digital, Photography, Teaching
}

\begin{abstract}
Because of the deep influence of traditional teaching mode, the present photography teaching in our country is a little lagged behind. After the arrival of digital age, the content and means of photography teaching has some new changes. Under this new situation, it is the only way to better improve students' aesthetic and creative ability that positively break off traditional teaching mode and further implement teaching reform. This paper lists the outstanding advantages of digital photography and discusses the teaching strategy of photography in the digital age.
\end{abstract}

\section{Introduction}

Photography course in colleges and universities is to cultivate students' ability to subtly find and capture good images, thus to take professional images more skilled and create high-quality photography works with high artistic level and technical connotation. In view of that photography course is with high practicalness and creativity, in order to better realize teaching goals, we should fully be suite to the requirement of the current digital age, drive teaching reform to find a teaching mode that more suitable to this course.

\section{Outstanding advantages of the digital photography}

Compared with traditional photography, digital photography has different nature, its shock shook the traditional photography that existed for hundred of years in a very short time, why? That needs to analyze the outstanding advantages of digital photography. The author thought that digital photography has following five advantages: one is that digital photography store with digital signals, it no needs to show image information like the traditional films, thus greatly shortened the photography process. Digital photography uses computer to process images, thus the photography production technique is easy to be grasped. Without usage of film can not only eliminate pollution caused by all kinds of chemicals but also can avoid the image loss caused by mistakes.On the other hand, digital photography saves a lot, it only needs digital camera and memory card, which can be used repeat, thus saved fees used to purchase films and other things for traditional photography. Thirdly, digital photography is with better quality. Because images taken by digital camera are stored in the digital way, thus can be transferred to other equipment, and the image quality will not be changed during the transition, while traditional washing level, film quality and paper quality will cause damage to the images. Fourthly, digital camera can present image immediately, if the image quality is not good, you can repeat take another one again and again until you are satisfied and you can immediately delete the unsatisfied images. Traditional image needs patience to wait, you will not know its quality until washed out. Fifthly, images taken by digital camera are easy to be copied, only need to copy it to the computer, can also put on one's homepage, QQ zone or the friends circle of Wechat. It is very convenient to tidy and store image in the digital way, you can find it immediately if you want, while traditional camera mainly depends on physical copy, its quality is easy to be damaged once without good storage.

\section{Strategy for photography teaching in the digital age}

Collect high-quality photography teaching materials.

Currently, photography teaching resources in the market of our country are uneven, contents of many photographic materials are not practical enough, all are written generally, difficulties and 
selective analysis are not outstanding enough. Though there are lots of photographic materials on the internet, it will consume much time for learners to find out the most suitable one. According to this situation, teachers are required to provide college students with more scientific and better quality teaching resources based their actual situation. The author thought resource construction for photography course can definitely depends on the core course of the college to realize. For the content of photography teaching, should delete the contents that out of date, such as photo washing; should delete the repeated contents, like optical basis; should suitably explore the current new photographic skill; should add in subjects like news photography, kids photography or wedding photography. Teachers can make use of the college's network system to make students share coursewares and teaching videos, thus convenient for students' after-class learning; can make college students share the latest photographic works to enlighten their thinking and stimulate their creation inspiration; can exhibit college students' photographic works to motivate their creation subjective initiative; can timely organize network answering questions, among which, teachers' courseware should service students' self-learning ability, but not just simply make PPT courseware, for example, when teach camera structure, teachers should use three-dimensional software to make a real interactive camera, thus, college students can know the specific structure of camera more comprehensive and more intuitive.When explain the field depth of camera, teachers can use multi-media courseware to show the scene virtually. Deepen students' understanding on the terminology-field depth of camera by using images taken by different aperture and shutter. Thus can better to stimulate students' vision and hearing to improve learning effects.

\section{Improve the content system of photography course.}

With the constant development of modern information technique and digital technology, influence of digitization on the living, work, study of modern people is becoming bigger and bigger, especially the digital image technology's revolutionary, subversive and thorough influence on the traditional photography technology. Because of the coverage of digital photography, we can only make a fully perceptions and thoughts on the current photography. We can realize the teaching goals of photography in colleges in the digital age through timely changing our point of view, follow up the space of technology development and comprehensively adjust the current photographic teaching materials. One one hand, set photographic technology and art as main content to change the former situation that with photographic equipment as main content. At present, the actual operation of camera becomes more and more simple. Therefore, the author cleared up the important contents that need students to grasp, based on the actual situation of photography teaching: First is the basic operation of camera. College students should comprehensively know all the specific parts of camera and their functions to grasp the main principle of photography and can take photo in a right way. This part of content can be changed based on students' proficiency. Second is to confirm exposure correctly. Reasonable exposure can be said as the important basis of successful photography. Only with reasonable exposure can rightly recovering color. Thus needs to learn reciprocity law, natural light and work light exposure. Third is to know the depth of field. The key to grasp the depth of field is to control the sharpness and virtual-real relation of the images and to express image in a better way. Fourth is to elaborately conceive photographic composition. This is an extremely important content in the photography. The success of a photographic work is not just exactly guarantee accurate exposure but more important to how to make composition and conception. This is the priority among priorities, thus at lest needs 1/4 time for teaching to make students grasp the method and skill of photography composition, and can put theory into practice. On the other hand is to emphasize the function of digital technology. Digital camera and traditional camera are the same on exposure and composition, but digital camera has advantages on the aspects of photography teaching, creation and media production. Therefore, should add contents of digital storage technology and digital image processing technology and cancel contents like darkroom technology. More important is that students should experience the huge advantage of digital photography as soon as possible.

\section{Introduce in multi-media teaching means.}

Multi-media teaching technology mainly means the technology that use computer to deal with all kind of multi-media information, it is the product of the digital age. Make reform for photography 
teaching is to comply with the real situation of the current society. The vivid features of multi-media technology are image with text, audio-visual blend and resource sharing. Multi-media teaching means can real realize to let learners as center, on strengthening communication, it helps teachers use all kinds of information to make on-site analysis and answering based on students' feedback, such as questions and reflections in the class, thus to make the relationship between teaching and learning become more closely. Use the feature of multi-media technology that man-machine interaction, especially use in the photography teaching reform, thus to have real positive meaning on quality-oriented education and cultivation of creative thinking ability of college students. Use multi-media technology in the photography teaching in colleges can make photography teaching especially photographic theory teaching become more intuitive and vivid. Fro example, when teaching camera structure, if use the traditional teaching mode, teachers need to draw the main structure of the camera on the blackboard, even though, students can only know the structure of important parts of camera. After using multi-media technology, college students can know every aspect of the camera more comprehensively. Based on the image-text description, and with voice explanation, students can learn photographic knowledge more intuitively and vividly. Use multi-media to take photo and process the photos. Presently, digital camera is popularized in college students, naturally melti-media means is used more and more often. Visibly, apply digital camera in the photography class can tightly contacts with multi-media technology, thus to contact the new taken images more intuitively in the shortest time. Compared with the traditional photography teaching, this not only shortened time but also improved teaching effects.

\section{Emphasize photography practice teaching.}

The practicality of photography course is very string, the whole teaching activities should combine theory with practice, introduce theory through practice, then strengthen practice by using theory, practical photograph in the teaching should be normalized, thus to get better effects. First is to implement topic photograph. Design the teaching content to one or many teaching task, thus to help college students finish photographic tasks, put theory into practice. College students are very clear about their own learning objectives and tasks, thus all of them are with enthusiasm, and can lead students to deeply understand the natural beauties. Second is to pay more attention to guiding students to grasp the application of photographic skills when arrange photographic tasks. Therefore, can arrange some special skills to finish photographic tasks, for example, to make students deep into the skill for using photographic equipment through follow shot, zooming shot and night shot. Third to let students operate by themselves, especially to use relevant image process software like Photoshop to make purpose production for the digital images taken by digital camera, positively explore the multi combination of visual elements in the image to enrich the image effect. Forth is to make photographic commendation. For photographic works of college students, firstly should let the creator to introduce the inner meaning of the work, then ask other students to express their understandings, at last, teachers to make commendation and summary, the importance is to let students realize the characteristic and deficiencies of their works, thus to have lessons to improve their creativity.

\section{Deepen the construction of assessment system for the photography teaching.}

Excellent assessment system can stimulate the learning enthusiasm of college students, therefore, it is very necessary to make a good assessment system. In order to improve students' passion on photography, should add personal assessment of student himself when do assessment, ask them to mark for themselves and their classmates. For the assessment score proportion, daily performance accounts for $20 \%$, assessment of the teacher accounts for $40 \%$, self-assessment and other classmates' assessment accounts for $40 \%$, thus, students' performance is not only controlled by teacher, but by teacher together with students, it can make students' performance more objective, meanwhile, can make students participate in the assessment to stimulate their learning enthusiasm, to realize the purpose of pushing learning through assessment. In order to better improve students' enthusiasm to achieve works with higher quality, the author thought can exhibit students' photographic works on the campus at the right time, thus to motivate them to create better works. 


\section{Conclusion}

In conclusion, the tight integration of theory and practice of the photography teaching in colleges both pays attention to students' independent inquiry and improves their enthusiasm. This requests teachers of photography teaching in colleges to follow up the development process of photographic equipment and new technology in the digital age, make the teaching concept and content advance with times, thus to comply the rapid development of current economic society, to make the photography education of our country get a better development.

\section{References}

[1] Zheng Chengyi. Digital Photographic Composition. Beijing: Posts \& Telecom Press,2009.

[2] Huang Xiaojun. Reform of Photography Teaching in Colleges based on the Digital Teaching Platform. Journal of Jiangxi College of Education,2010(6).

[3] Yao Yongming. Discussion on the Photographic Multi-Media Teaching in the Network Digital Age. Computer Knowledge and Technology,2011(11).

[4] Li Hualai, Shen Lingling. Construction of Digital Photographic Teaching Mode. Journal of Huaihai Institute of Technology (Humanity and Social Science Edition), 2013(20). 